\title{
Comparison of Comprehensive Mean Difference of Educational Level Between Urban and Rural Population in Rajasthan
}

\author{
Dr. Shahid Imam \\ Associate Professor, Ex. Head, Department of Geography, D.S.College, Aligarh, India \\ imamshahid@rediffmail.com
}

\begin{abstract}
The present research paper attempts to analyse the trends of urban-rural literacy rate and their differential both in Rajasthan and India as a whole from 1951 to 2011. Purpose of this research paper is also to analyse the regional pattern of literacy rate at district level in Rajasthan on the basis of census report of 2011. This research paper also studies the spatial pattern of urban-rural differential in literacy rate at district level and its relationship with twenty four other independent variables to assess the level of development. The urban rural differential in literacy rate is found to be narrowing down from 1951 to 2011 in the state of Rajasthan. At district level it has been observed that the western and southern districts indicate very high urban rural differential index, because of less developed economic and social conditions. Whereas, the urban rural differential indices have been found to be low in northern and eastern part of the state. Study reveals that out of twenty four variables, eleven are significant at $99 \%$ level of confidence in their relationship with urban rural differential index, whereas, other five variables are significantly correlated at $95 \%$ level of confidence.
\end{abstract}

Keywords: Literacy rate, Rajasthan, Rural literacy, Urban literacy, Literacy differential

\section{Introduction}

One of the biggest and the most difficult issue, which the people of the developing countries like India, facing today is literacy, as India and other developing countries are characterized by low level of literacy rate. Literacy has been considered as a human right, which leads to socio-economic development and ultimately the cultural progress of the human society. Literacy may also be considered as a tool for empowerment of the individual and is also considered as an important component of human development index, will lead towards a process of modernization of the society, which will ultimately bring change in overall culture. Literacy helps in developing the bond in the society and reduces poverty, which ultimately leads to improvement in the standard of living of the people. Literacy acts like a catalyst in building a good social and good socio-economic infrastructure. Society having higher literacy rate always finds it better than the society having low literacy rate. Literacy being the main component of human development index, has got its direct impact on per capita income, living standard and even the life expectancy. High literacy rate accelerates the pace of development of any region, as the development and literacy rate has a positive correlation. Literacy has a direct impact on the people's attitude, because it influences fertility, mortality, sex ratio and even the mobility of the people, because literates are more mobile as compared to illiterates. It is only because of the fact that literacy helps people to make right decision at the right time. Literacy affects almost every sphere of the society, like, population control, health, hygiene, environmental awareness, women empowerment, political consciousness as well as the poverty ridden society.

The definition of literacy has changed over time, but now, according to the census of India, literacy has been defined as an ability to read and write with understanding in any language. Children below seven years of age are treated as an illiterate in our country. Whereas, UNESCO defined literacy as the ability to identify, understand, interpret, create, compute and use of printed and written material associated with varying contracts. According to census of India, children below the age of 5 years were considered as an illiterate in the census 1961, 1971 and 1981. Since, 1946, UNESCO has been in forefront in advancing the vision of literate world and acquiring and improving literacy skills has been considered as a part of the right to education, which leads to empowerment of the people, participation of the people in the improvement of the society as well as contribution to improved livelihoods. Developing countries like India is not only characterized by low literacy rate, but also there exists disparities between rural and urban literacy rate, male and female literacy rate and even between young and aged, as well as disparity at regional level. One of the most important aspects of literacy differentials in the country relates to urbanrural gap in literacy rates. It is so pervasive that it exists in total population as well as gap in male and female literacy rate and in different magnitude in all social life. But with the onset of literacy transition in our society, the urban rural differential in literacy rate has been continuously narrowing down both in the country as well as in the state of Rajasthan, and can be suggested that the transition in literacy rate has been approaching very fast towards the advanced stage. The differences in urban-rural literacy rate results from the sharp variations in socio-economic condition of urban and rural area in India. The economy of rural area does not support properly to the formal education and skill, because rural economy predominantly depends upon primary sector i.e., agriculture, whereas, the urban economy depends largely upon secondary and tertiary sector, which necessarily requires minimum level of literacy. In addition, there is marked variation in the level of educational facilities in the urban and rural areas. Apart from this there has been a continuous migration of literate people from rural to urban areas in search of good jobs and amenities and facilities, which also results in lower level of literacy rate in rural areas. Therefore, urban and rural differential in literacy rate is 
essentially a function of different rate of changes occurring in urban and rural areas. Like other innovations, literacy disseminates first in urban areas and diffuses subsequently in rural areas. The disparities between urban and rural literacy rate also depends up the degree of urban influences on rural area as well as the level of interaction between urban and rural areas. Rural literacy rate may also be influenced by diversity in economic activities of the rural area.

\section{Objectives}

The present research paper attempts to study the district level variation in urban-rural differentials in literacy rate in the state of Rajasthan, with the following objectives:

- To examine the disparities in urban-rural literacy rate and its differentials in the districts of Rajasthan.

- To examine the trends of urban-rural differentiates in literacy rate in India and Rajasthan from 1951 to 2011.

- To examine the relationship between rural and urban literacy rate.

- To analyse the relationship between urban-rural differentials in literacy rate and development variables obtained from districts census handbook.

\section{Database and Methodology}

The study is mainly based on secondary source of data. The data and information has been collected from district census Handbook 2011, obtained from the Office of the Registrar General of India and Census Commissioner, Government of India. The district has been considered on the smallest unit of study. In the present research paper most suitable statistical techniques like percentage and Karl Pearson's Coefficient of correlation have been adopted to find out the relationship between urban-rural differential in literacy rate and other twenty four independent developmental variables. As well as their level of significance were tested out at $95 \%$ and $99 \%$ confidence level. Before calculating correlation, percentage were worked out for all the variables except sex ratio and density of population.

To find out the urban-rural differential in literacy rate, following formula given by Krishna and Shyam 1978 has been used:

Where:

$$
\mathrm{ID}=\frac{\mathrm{U}-\mathrm{R}}{\mathrm{T}}
$$

ID = Index of urban-rural differential in literacy rate.

$\mathrm{U}=$ Literate urban population in percentage

$\mathrm{R}=$ Literate rural population in percentage

$\mathrm{T}=$ Total literate population in percentage

For Rajasthan 2011, this index would be:

$$
\frac{79.68-61.44}{66.11}=0.28
$$

Apart from the above statistical techniques, cartographic methods like Bar graph, line graph and choropleth maps have been used to represent the statistical data obtained from different economic sources.

\section{Study Area}

Rajasthan, the land of king comprises erstwhile Rajput kingdom, Muslim kingdom as well as two Jat kingdoms. Rajasthan the largest state of India, includes most of the Rajputana, with a total area of 342239 sq.km. Rajasthan is the home of diversity and is located on the north-western part of the country. The state of Rajasthan was formed on $30^{\text {th }}$ March 1949 and Jaipur being the largest city was declared as the capital of state. Rajasthan is located between $23^{\circ} 30^{\prime}$ north and $30^{\circ} 11^{\prime}$ north latitude and 69 $29^{\prime}$ east and $78^{\circ} 17^{\prime}$ east longitude. Rajasthan located in the northwestern part of the country includes the ruins of Indus valley civilization as well as temples, forts and fortresses are almost in every districts of Rajasthan. Rajasthan is bounded on the west and northwest by Pakistan, on the north and northeast by the states of Punjab and Haryana and Uttar Pradesh, on the east and southeast by the state of Uttar Pradesh and Madhya Pradesh, whereas Gujarat is located on the southwest of the state. In Banswara district, which is located on the extreme southern tip of the state Rajasthan, tropic of cancer passes through it. Thar Desert which is located in the western part of Rajasthan is characterized by relatively dry and infertile land covered with sands. Whereas, southwestern part of the state is characterized by somewhat wetter, hilly and fertile land. Infertile Thar Desert or Great Indian Desert occupies 19.84 million hectare of land, in other words, 58 percent of the total geographical area of the state of Rajasthan and 6 per cent of the total geographical area of India. In spite of the varying topography, substantial part of Rajasthan is covered by low to medium height sand dunes. Rajasthan experiences varying climatic conditions throughout its land. It is hot and very dry in summer and cold during winter in the desert region, but east of the Aravalli mountain experiences comparatively better rainfall and therefore, high humidity. The western desert experiences a rainfall of $100 \mathrm{~mm}$ (about 4 inch) annually whereas; the south western part receives somewhat better rainfall of $650 \mathrm{~mm}(26 \mathrm{inch})$ annually. The rainy season lasts for very short period from July through September, during monsoon season. Apart from river Ghaggar, which flows through Hanumangarh, and Sri Ganganagar district, there is one small river known as Kakni, which flows in Jaisalmer.

According to 2011 census report, total population of Rajasthan is 68548437 , which is almost 5.66 percent of the country's population and occupies the status of $8^{\text {th }}$ most populous state of India. The growth of population during 2001-2011, is 21.31 percent, whereas in the previous decade it was 28.33 percent. The density of population is 200 persons per sq.km., which is much below the national average of 382 persons per sq.km. Whereas, Rajasthan registered a sex ratio of 928 females per thousand males.

As far as the literacy rate of Rajasthan is concerned it is 66.11 percent in the census year 2011. Out of the total male population of 35550997 persons, 79.2 percent are literate, whereas, out of total 32997440 female population, 52.1 percent are literate. Average literacy rate of urban area in Rajasthan is 79.68 percent, which constitutes 87.91 percent males and 63.81 percent females; whereas the literacy rate in rural area is 61.44 percent. 


\section{Trends of urban-rural differential in literacy rate (1951-} 2011)

As it is evident from the fact that Rajasthan was formed on $30^{\text {th }}$ March 1949, therefore differential in literacy rate by residence will be possible from 1951. It is only because of this fact that the trends of urban-rural differential in literacy rate has been analysed since 1951 and a comparative study of Rajasthan has been made with country as a whole. There is a wide gap in the rural and urban literacy rate, both in state as well as country as a whole, since 1951 to 2011 . However, it is narrowing down with the passage of time. Table 1 reveals that the literacy rate of Rajasthan was only 8.38 percent in 1951 as compared to national average literacy rate of 18.3 percent. Census year 1961 recorded a jump from 8.38 in 1951 to 15.21 percent in 1961 as compared to 28.3 percent in the country as a whole, which is 13.09 percentage lesser. Since 1961 there has been a continuous growth in the literacy rate of Rajasthan as well as India as a whole, census year 1971 recorded a growth of 3.86 percentage point, with a literacy rate of 19.07

Table 1: Literacy Rate and Differential Index, Rajasthan and India (1951 to 2011)

\begin{tabular}{|c|c|c|c|c|c|c|c|c|}
\hline \multirow[t]{2}{*}{ Year } & \multicolumn{3}{|c|}{ Rajasthan } & \multirow{2}{*}{$\begin{array}{c}\text { Urban-rural } \\
\text { differential index }\end{array}$} & \multicolumn{3}{|c|}{ India } & \multirow{2}{*}{$\begin{array}{c}\text { Urban-rural } \\
\text { differential index }\end{array}$} \\
\hline & Total & Rural & Urban & & Total & Rural & Urban & \\
\hline 1951 & $8.38 *$ & $4.97 *$ & $24.68 *$ & 2.35 & 18.3 & 12.1 & 34.6 & 1.23 \\
\hline 1961 & 15.21 & 10.85 & 37.61 & 1.76 & 28.3 & 22.50 & 54.40 & 1.13 \\
\hline 1971 & 19.07 & 13.85 & 43.47 & 1.55 & 34.5 & 27.89 & 60.22 & 0.94 \\
\hline 1981 & 24.38 & 17.99 & 48.35 & 1.25 & 43.6 & 36.01 & 67.23 & 0.72 \\
\hline 1991 & 30.79 & 24.10 & 53.35 & 0.95 & 52.2 & 44.69 & 73.08 & 0.54 \\
\hline 2001 & 60.41 & 55.34 & 76.20 & 0.35 & 64.84 & 58.74 & 79.92 & 0.33 \\
\hline 2011 & 66.11 & 61.44 & 79.68 & 0.28 & 74.04 & 68.91 & 84.98 & 0.22 \\
\hline
\end{tabular}

\section{Sources:}

Some facts about Rajasthan, 2014, Department of Planning, Directorate of Economics \& Statistics, Rajasthan, Jaipur-302005 Population Facts and figures, Rajasthan (1961-2001), directorate of Economics and Statistics, Rajasthan, Jaipur.

*Calculated by author on the basis of data given in Census of India 1951 Volume X Rajasthan and Ajmer Part-II A Rajasthan Profile, Census Info India, 2011, Final Population Totals.

Note: Urban-rural differential index, calculated by author.

percent in Rajasthan, whereas country as a whole recorded a growth of 6.2 percentage point. Census year 2001 recorded a growth of 29.62 percentage point which is the highest growth in literacy rate since 1961 to 2011, in Rajasthan, whereas, India as a whole recorded a growth of only 12.64 percentage point in the same census year, which is much less than the growth of literacy rate in Rajasthan. In spite of continuous increase in literacy rate since 1961, Rajasthan recorded a literacy rate of 66.11 percent in 2011, which is 7.93 percentage point lesser than the average literacy rate of India (74.04 percent).

If we go through the literacy rate of urban areas in Rajasthan we find that in 1951 it was only 24.68 percent, whereas, national average urban literacy rate was 34.6 percent, which is 9.92 higher than the state of Rajasthan. In Rajasthan, census year 1961 registered a literacy rate of 37.61 percent, which is 16.79 percentage point lesser than the average urban literacy rate of India as a whole. In 1971, the urban literacy rate of Rajasthan rose to 43.47 percent which is still 16.75 percentage point, almost similar to the previous decade, lesser than the nation average urban literacy rate of India $(60.22$ percent). The highest growth of urban literacy rate in Rajasthan was observed in the census year 2001, with a growth of 22.85 percentage point, whereas India as a whole recorded a growth of only 6.84 percentage point in the same census with a literacy rate of 79.92 percent, which is much less than the growth rate in Rajasthan. Census year 2011 recorded an urban literacy rate of 79.68 percent in Rajasthan which is 11.9 percentage point less than the urban literacy rate of India (84.98 percent).

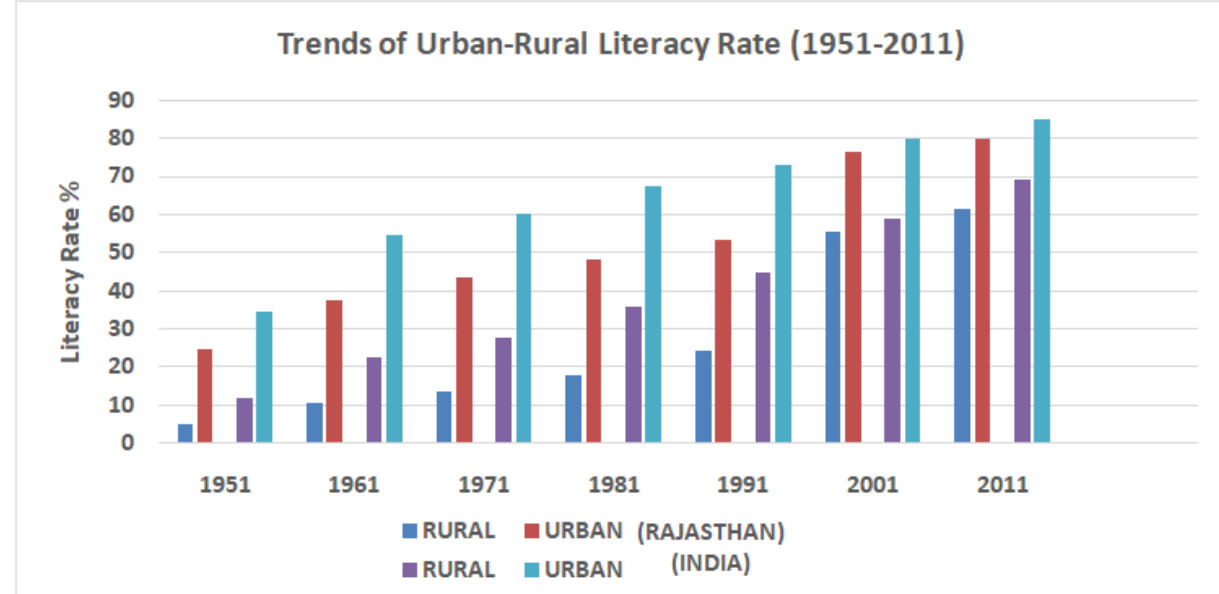

Rural Rajasthan recorded a literacy rate of only 4.97 percent in 1951 as compared to 12.1 percent as a national average rural literacy rate which is 7.13 percentage point lesser. In rural area, literacy rate was recorded at 10.85 percent in Rajasthan which is 11.65 percentage point lesser than the average rural literacy rate of India as a whole in the census 
year 1961. Census year 1971 recorded a rural literacy rate of 13.85 percent in Rajasthan which is only 3 percentage point higher than the census year 1961, whereas, India as a whole recorded a rural literacy rate of 27.89 percent, in the same census year (1971), which is 5.39 percentage point higher than the previous census year and 2.39 percentage point higher than the growth in rural literacy rate $(3$ percentage point) in Rajasthan. Census year 1981 registered a rural literacy rate of 17.99 percent, which rose to 24.10 percent in 1991 , but the highest growth in rural literacy rate was recorded in the census year 2001, with a growth of 31.24 percentage point and a literacy rate of 55.34 percent. It also recorded the highest growth rate in rural literacy rate in the census year 2001, with a growth of 14.05 percentage point, which is almost half of the percentage growth of rural literacy rate in Rajasthan (31.24 percentage point).

After the formation of Rajasthan in 1949, raising literacy was a very difficult task in Rajasthan because of vast poverty, demolished economy, low level of employment, low level of productivity as well as initial stage of industry like small cottage industries. It was also very difficult to raise the level of literacy and education amongst the weaker section of the society. Therefore, government made a lot of efforts to raise the literacy level in Rajasthan as well as in the country as a whole by means of formation and implementation of various schemes/programmes, like National Literacy Mission (NLM), Total Literacy Campaign (TLC), Sarva Shiksha Abhiyan and Operation Blackboard, etc., Therefore, overall literacy rate has been improved since 1951 to 2011. It is however, a well-known fact that the improvement in literacy rate mainly remained concentrated in urban area of Rajasthan and rural areas lagged behind urban area with a wider gap. It is important to mention here, and is also an encouraging fact the census year 2001 recorded the higher growth in rural literacy rate (31.24 percentage point) from the previous census year (1991), as compared to the growth in urban literacy rate (22.85 percentage point) which shows a differences of 8.39 percentage point.

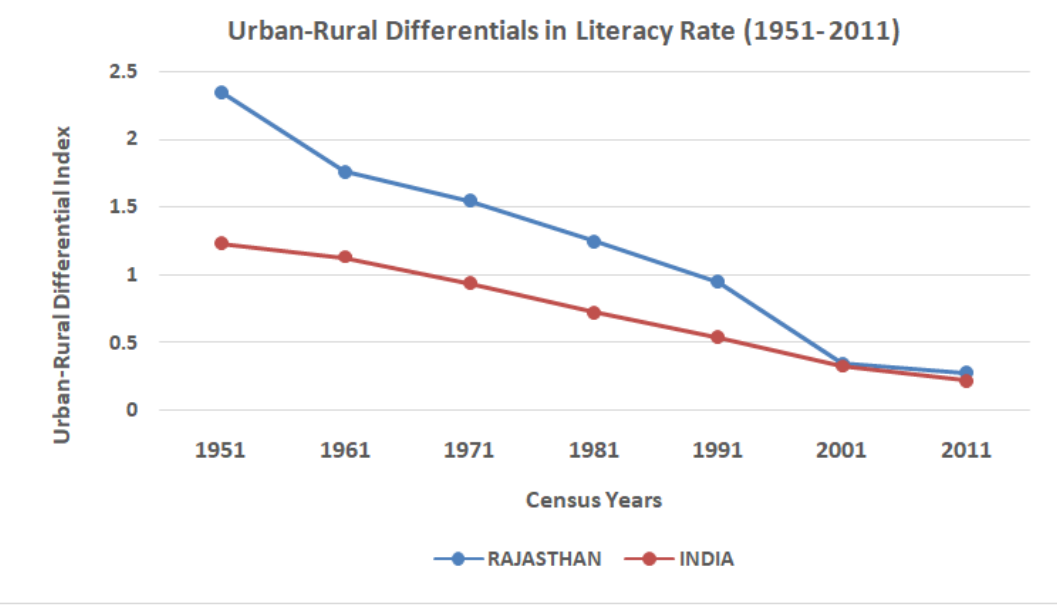

Urban-rural differential index in literacy rate, both in India as a whole and Rajasthan exhibit a decreasing trend. Rajasthan in the census year 1951 recorded an urban rural differential index of 2.35 percentage point, whereas, India as a whole registered an urban rural differential index of only 1.23 percentage point. Census year 1961 registered a sharp decline in urban-rural differential index of 1.76 percentage point in Rajasthan, but it is higher than the urban-rural differential index of India as a whole (1.13 percentage point). Since 1961, there has been a continuous decline in urban-rural differential index. In 1971 it decreased to 1.55 percentage point and in 1981 it decreased to 1.25 percentage point. After 1981, differential index reflects a positive scenario in Rajasthan because 1991 registered a sharp decline from 1.25 percentage point in 1981 to 0.95 percentage point in $1991,0.35$ percentage point in 2001 and only 0.28 percentage point in 2011. The urban rural differential index in India also reflects positive scenario since 1961 to2011. Urban-rural differential index registered a sharp decline, from 1.13 percentage point in 1961 to 0.94 percentage point in 1971 , and declined to 0.72 in 1981, 0.54 in 1991, 0.33 in 2001 and 0.22 in 2011, which is 0.06 point lesser than the urban-rural differential index of Rajasthan. This sharper decline in urban-rural differential index both in Rajasthan and India as a whole, indicates that the people living in rural areas have gradually become conscious toward education, which can be attributed to the fact that the interaction between urban and rural area has increased manifold due to development in communication facilities. This interaction of rural areas with urban area led to the improvement in socio-economic conditions, which ultimately helped people to understand the value of education, which led to opening of new schools and colleges even in the rural areas.

\section{Pattern of Urban-Rural Literacy Rate}

Any economy whether it is developed or developing, education is one of the important factor in economic growth and human development. Human society can flourish only when the human resources can be used in its fullest form. In the state of Rajasthan, the improvement in literacy rate has been spectacular in the census report of 2001. Census of 2001 shows that Rajasthan has recorded the highest literacy rate among all the states in India, with a literacy rate of 60.41 percent, which is 29.62 percentage point higher than the previous decade 1991. If we compare the literacy rate Rajasthan in 2001 with the literacy rate of India, we find that India recorded a literacy rate of 64.84 percent, which is 4.43 percentage point higher than Rajasthan but there is a growth of only 12.64 percentage point from the previous census year 
of 1991, which is much less than the growth of literacy rate in Rajasthan (29.62 percentage point).

According to 2011 census report Rajasthan has recorded a total literacy rate of 66.11 percent, which is just 5.7 percentage point higher than the census year 2001, and is also much lesser than the literacy rate of India (74.04 percent). The literacy rate has been spectacular in Jhunjhunu (74.1), Alwar (70.7), Bharatpur (70.1), Jaipur (75.5), Sikar (71.9) and Kota
(76.06). The regional pattern of urban and rural literacy rate shows variation at all level. If we go through the rural literacy rate in 2011, we find that highest rural literacy rate has been recorded in Jhunjhunu, with a rural literacy rate of 73.4 percent which is followed by Sikar (70.8), Kota (68.6) and Dhaulpur (68.1), whereas the lowest literacy rate has been observed by district Sirohi with a literacy rate of 49 percent, which is 12.4 percentage point less than the state average rural literacy rate (61.4).

Table 2: District Wise Literacy Rate and Urban Rural Differential in Literacy Rate (2011)

\begin{tabular}{|c|c|c|c|c|c|c|c|c|c|c|c|}
\hline S.N & District & Total & Rural & Urban & Differential index & S.N & District & Total & Rural & Urban & Differential index \\
\hline 1 & RAJASTHAN & 66.1 & 61.4 & 79.70 & 0.28 & 18 & Barmer & 56.5 & 54.8 & 78.20 & 0.41 \\
\hline 2 & Ganganagar & 69.6 & 66.2 & 78.70 & 0.18 & 19 & Jalor & 54.9 & 53.3 & 71.10 & 0.32 \\
\hline 3 & Hanumangarh & 67.1 & 65.1 & 75.40 & 0.15 & 20 & Sirohi & 55.3 & 49 & 78.70 & 0.54 \\
\hline 4 & Bikaner & 65.1 & 58.1 & 78.00 & 0.31 & 21 & Pali & 62.4 & 58.4 & 75.80 & 0.28 \\
\hline 5 & Churu & 66.8 & 64.4 & 72.60 & 0.12 & 22 & Ajmer & 69.3 & 59.1 & 83.90 & 0.36 \\
\hline 6 & Jhunjhunun & 74.1 & 73.4 & 76.50 & 0.04 & 23 & Tonk & 61.6 & 58 & 73.80 & 0.26 \\
\hline 7 & Alwar & 70.7 & 67.9 & 83.40 & 0.22 & 24 & Bundi & 61.5 & 57.3 & 77.90 & 0.33 \\
\hline 8 & Bharatpur & 70.1 & 67.9 & 79.00 & 0.16 & 25 & Bhilwara & 61.4 & 56 & 80.70 & 0.40 \\
\hline 9 & Dhaulpur & 69.1 & 68.1 & 72.70 & 0.07 & 26 & Rajsamand & 63.1 & 59.5 & 81.90 & 0.35 \\
\hline 10 & Karauli & 66.2 & 65 & 72.80 & 0.12 & 27 & Dungarpur & 59.5 & 57.6 & 84.40 & 0.45 \\
\hline 11 & Sawai Madhopur & 65.4 & 61.9 & 79.00 & 0.26 & 28 & Banswara & 56.3 & 54 & 85.20 & 0.55 \\
\hline 12 & Dausa & 68.2 & 66.3 & 80.70 & 0.21 & 29 & Chittaurgarh & 61.7 & 56.8 & 82.70 & 0.42 \\
\hline 13 & Jaipur & 75.5 & 67.6 & 82.50 & 0.20 & 30 & Kota & 76.6 & 68.6 & 81.70 & 0.17 \\
\hline 14 & Sikar & 71.9 & 70.8 & 75.40 & 0.06 & 31 & Baran & 66.7 & 63.6 & 78.00 & 0.22 \\
\hline 15 & Nagaur & 62.8 & 60.9 & 70.60 & 0.15 & 32 & Jhalawar & 61.5 & 57.6 & 81.10 & 0.38 \\
\hline 16 & Jodhpur & 65.9 & 58.5 & 79.40 & 0.32 & 33 & Udaipur & 61.8 & 54.9 & 87.50 & 0.53 \\
\hline 17 & Jaisalmer & 57.2 & 53.8 & 78.00 & 0.42 & 34 & Pratapgarh & 56 & 53.2 & 84.80 & 0.56 \\
\hline
\end{tabular}

Source: Rajasthan Profile, Census Info India, 2011, Final Population Totals.

The districts, with reference to the rural literacy rate in 2011, have been categorized in five categories, low (below 50 percent), medium (50.01 to 60percent), high (60.01 to 70percent), and very high (above 70percent). The data regarding rural literacy rate reveals that, out of 33 districts in Rajasthan there is only one district, named as Sirohi (49 percent) which can be categorized under low level of rural literacy rate which is located in southwestern part of the state and constitute only 1.50 percent of total area of Rajasthan, whereas seventeen districts, named as, Bikaner (58.1), Jodhpur (58.5), Pali (58.4), Ajmer (59.1), Tonk (58), Bundi (57.3), Jaisalmer (53.8), Barmer (54.8), Jalor (53.3), Bhilwara (56), Rajsamand (59.5) Dungarpur (57.61), Banswara (54), Chittaurgarh (56.8), Jhalawar (57.6), Udaipur (54.9) and Pratapgarh (53.2) are categorized under moderate level of rural literacy rate.Out of these seventeen districts, Bikaner,
Barmer and Jaisalmer are located in the western part of Rajasthan. All these seventeen districts, which are categorized under moderate level of rural literacy rate, constitute 63.69 percent of the total area of Rajasthan. Apart from the above mentioned eighteen districts, there are thirteen districts, named as, Ganganagar (66.2), Hanumangarh (65.1), Churu (64.4), Alwar (67.9), Bharatpur (67.9), Dhaulpur (68.1), Karauli (65), Sawai Madhopur (61.9), Dausa (66.3), Jaipur (67.6), Nagaur (60.9), Kota (68.6) and Baran (63.6), which can be categorized under high level of literacy and constitutes 30.82 percent of the total geographical area of Rajasthan, whereas there are only two districts, named as Jhunjhunu and Sikar which are categorized under very high level of literacy rate above 70 percent and constitute only 3.99 percent of the total geographical area of Rajasthan. 


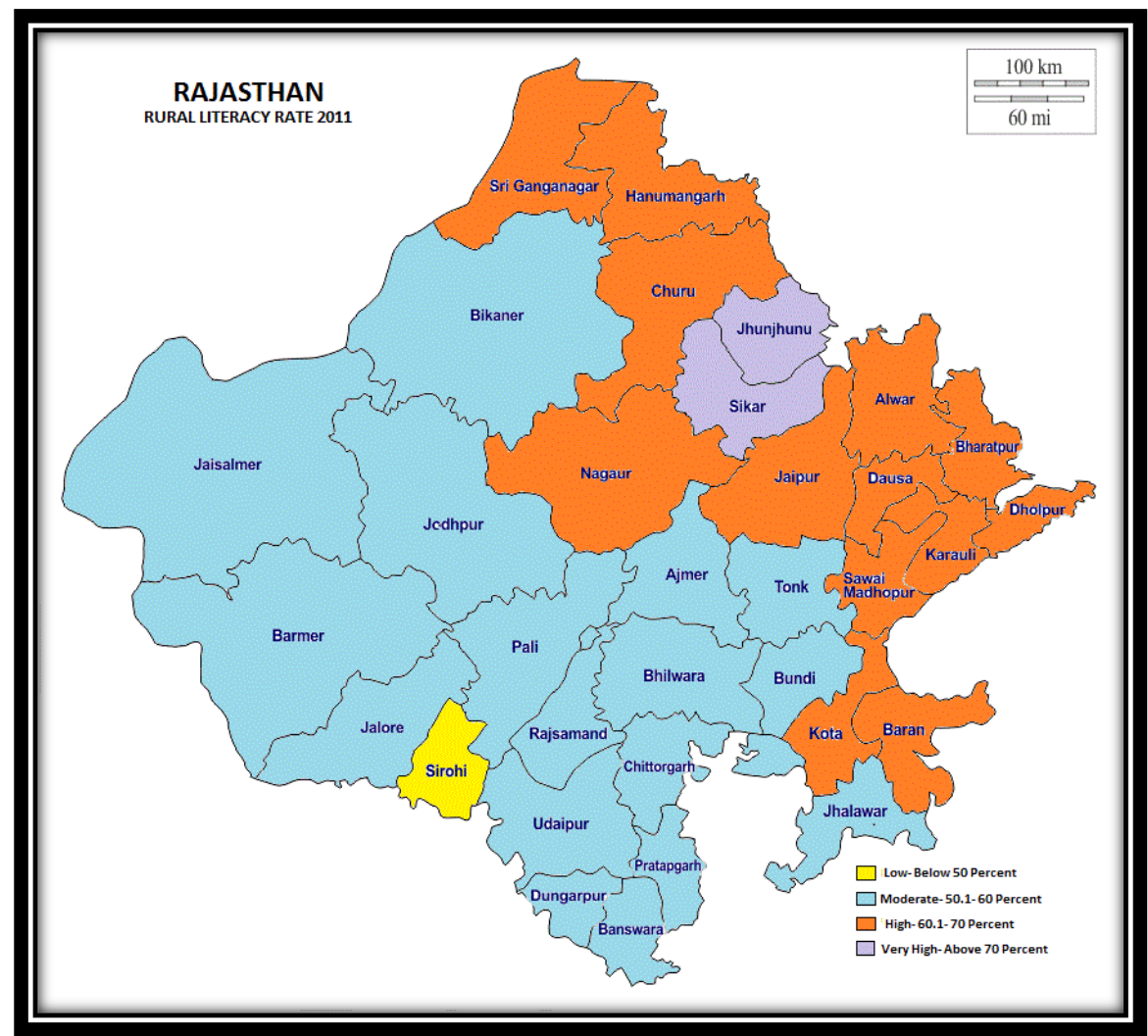

If we go through the urban literacy rate we find that the urban literacy among all the districts of Rajasthan, we find that there are thirteen districts, which have recorded urban literacy rate higher than the state average urban literacy rate of 79.70 percent. Among all the districts of Rajasthan, Udaipur recorded the highest urban literacy rate with a literacy rate of 87.50 percent, which is followed by Banswara (85.20) and Ajmer (83.90), whereas, the lowest urban literacy rate has been recorded by Nagaur with a literacy rate of 70.60 percent.

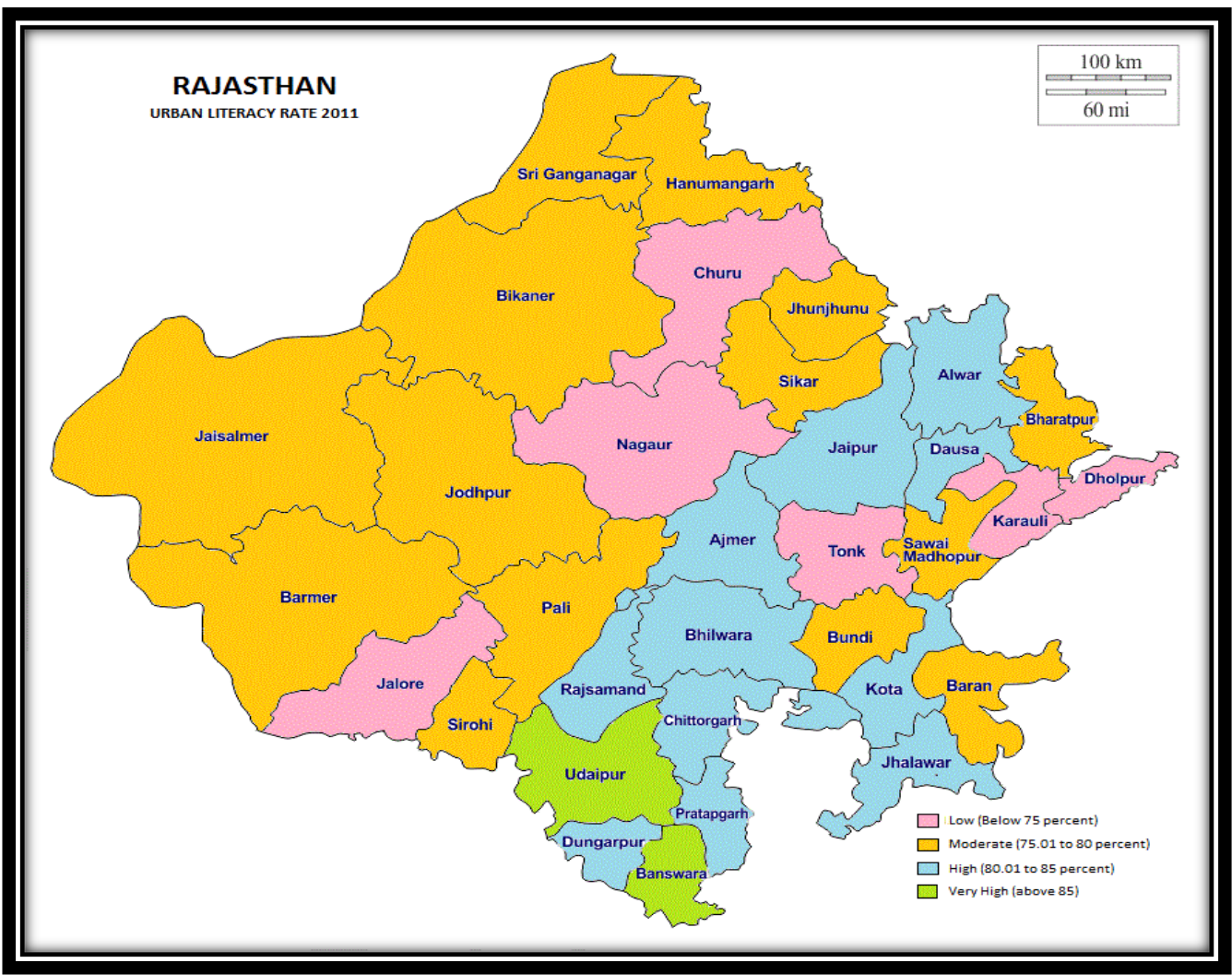

If we divide all the 33 districts of Rajasthan into low (below 75 percent), moderate ( 75.01 to 80 percent), high ( 80.01 to 85 percent) and very high (above 85 ), we find that there are six districts, which can be categorized under low level of urban literacy rate, named as Churu (72.60), Dhaulpur (70.70), Karauli (72.80), Nagaur (70.60), Jalor (71.10) and Tonk 
(73.80), which constitute of 16.93 percentof total geographical area of Rajasthan. There are fourteen districts named as, Ganganagar (78.70), Hanumangarh (75.40), Bikaner (78.00), Jhunjhunu (76.50), Bharatpur (79.00), Sawai Madhopur (79.00), Sikar (75.40), Jodhpur (79.40), Jaisalmer (78.00), Barmer (78.20), Sirohi (78.70), Pali (75.80), Bundi (77.90) and Baran (78.00) can be categorized under moderate level of urban literacy rate and covers a prominent region of Rajasthan comprising 56.69 percent of the total geographical area of Rajasthan. There are eleven districts which can be categorized under high level of urban literacy rate (80.01 to 85 percent), named as Alwar (83.40), Dausa (80.70), Jaipur (82.50), Ajmer (83.90), Bhilwara (80.70), Rajsamand (81.90), Dungarpur (84.40), Chittaurgarh (82.70), Kota (81.70), Jhalawar (81.10) and Pratapgarh (84.80). Therefore, a major part of Rajasthan has been categorized under high level of literacy rate and constitute 21.63 percent of the geographical area of Rajasthan. Most of the districts, categorized under high level of urban literacy rate are eastern districts. Out of 33 districts of Rajasthan only two districts, named as Banswara (85.20) and Udaipur (87.50) are categorized under very high level of literacy rate. Both these two districts are located in the southern part of Rajasthan and constitute only 4.75 percent of the total geographical area of Rajasthan.

\section{Urban-Rural Differentials}

It has already been observed that there is a wide gap between the rural urban literacy rate in Rajasthan; but the state level urban-rural differential index since 1951 to 2011, clearly indicates that, it has been continuously narrowing down from 2.35 percentage point in 1951 to 0.28 percentage point in 2011. If we go through the urban-rural different index in literacy rate at district level, we find that there is a notable variation in differential index among all the 33 districts of Rajasthan. The urban-rural differential index varies from 0.56 in Pratapgarh to 0.04 in Jhunjhunu, with a state average of
0.28 . Table 2 reveals that, out of 33 districts of Rajasthan 16 recorded an urban-rural differential index higher than the state average of 0.28 . It means there is wider gap between the literacy rate in urban and rural area over almost half of the districts of Rajasthan, however it is narrowing down, with the passage of time. All the 33 districts of Rajasthan can be conveniently grouped into four categories on the basis of urban rural differentials index to understand the spatial pattern of urban-rural literacy rate. Districts of Rajasthan can be categorized into low (below 0.09 ), moderate ( 0.10 to 0.29 ), high ( 0.30 to 0.49$)$ and very high (0.50 and above). On the basis of this categorization we can categorize three districts, named as Jhunjhunu (0.04), Dhaulpur (0.07) and Sikar (0.06) under low level of urban rural differential index, and are much below the state average urban rural differential index of 0.28 . Jhunjhunu and Sikar are located in the northern part, whereas Dhaulpur is located in the eastern side of the state and their border is shared by Haryana in northeast and Uttar Pradesh in east. The low urban-rural differential index below 0.09 reflects that there is no significant difference between the rural and urban literacy rate in these three districts. This minimization in urban and rural literacy rate may be attributed to the fact that, because of the proximity to Haryana and Uttar Pradesh, rural people in these districts might have become conscious regarding education and have become more aware about the benefits of education. Apart from this government has initiated several programmes to increase the literacy rate in the state as well as country as a whole. Out of 33 districts in Rajasthan, fourteen districts, named as Ganganagar (0.18), Hanumangarh (0.15), Churu (0.12), Alwar (0.22), Bharatpur (0.16), Karauli (0.12), Sawai Madhopur (0.26), Dausa (0.21), Jaipur (0.20), Nagaur (0.15), Pali (0.28), Tonk (0.26), Kota (0.17) and Baran (0.22) fall under moderate urban-rural differential index between 0.10 to 0.29 . Out of these fourteen district, one district, named as Pali

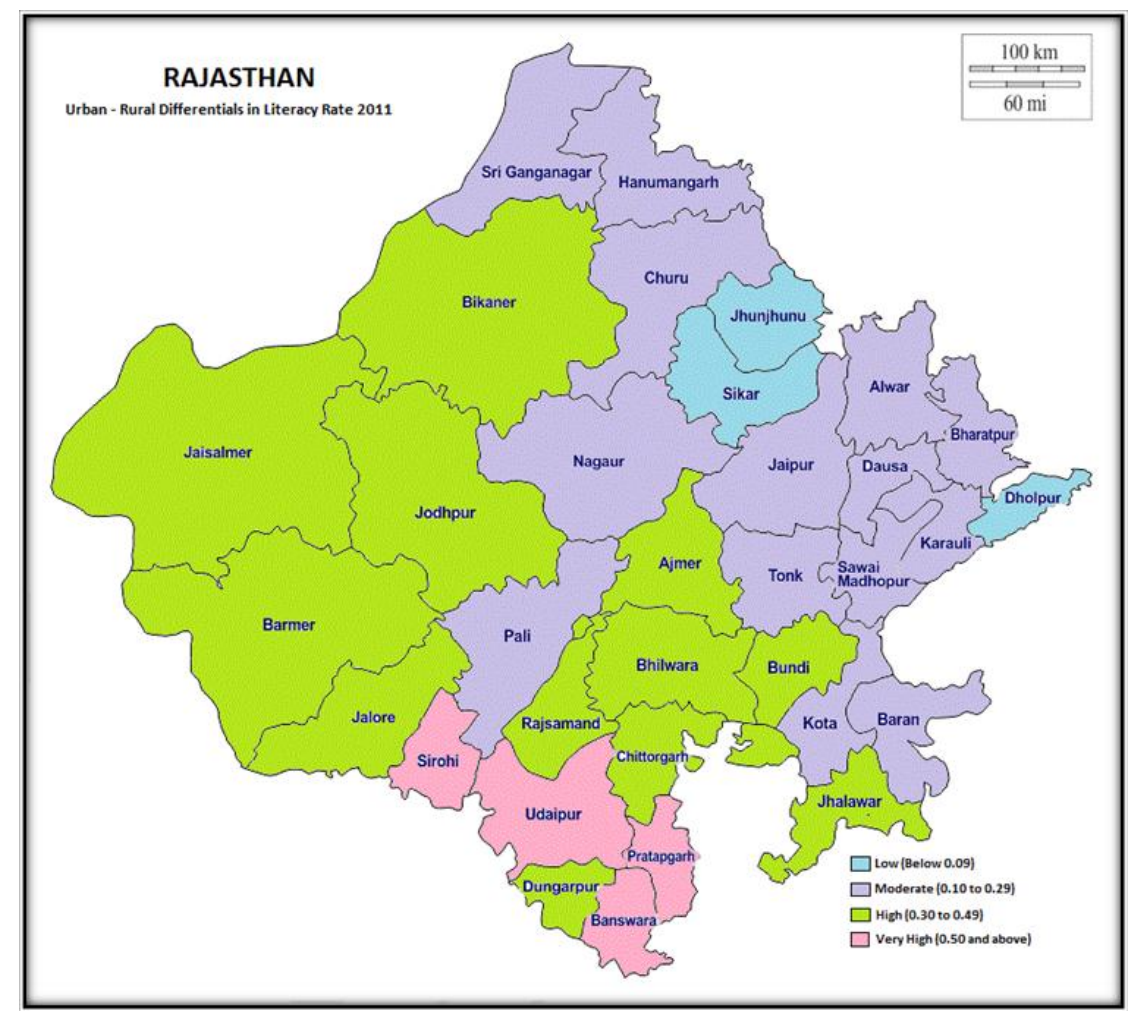


records the urban rural differential index similar to the state, 0.28. Whereas, there are five district named as Alwar, Sawai Madhopur, Dausa, Tonk and Baran recorded urban-rural differential index higher than 0.22 and are closer to the state urban-rural differential index (0.28). Moderate urban rural differential index reflects that, there is an increasing emphasis on raising literacy rate in rural areas by means of the various policy measures adopted by the government as well as younger generation are becoming aware of the importance of education and a generation gap can be visible in the society in terms of their education. Apart from this due to female prejudice people are not willing to send their girl child to school, but now a days situation has somewhat changed due to awareness programmes initiated by government.

There are twelve districts, named as Bikaner (0.31), Jodhpur (0.32), Jaisalmer (0.42), Barmer (0.41), Jalor (0.32), Ajmer (0.36), Bundi (0.33), Bhilwara (0.40), Rajsamand (0.35), Dungarpur (0.45), Chittaurgarh (0.42) and Jhalawar (0.38), can be categorized under high urban rural differential in literacy rate ranging from 0.30 to 0.49 percentage point. Most of these district are located along the western and southern part of Rajasthan, and is evident that the western part of Rajasthan especially the desert land like Jaisalmer is characterized by killing of girl child in the villages, and may be due to illiteracy prevailing among them. Most of these districts reveals urban rural differential index much higher than the state average. These districts are characterized by wider gap between urban and rural literacy rate. Out of twelve districts six districts reveals urban literacy rate higher than 80 percent, and rest of the districts revealed urban literacy rate higher than 70 percent, whereas all the twelve districts revealed rural literacy rate less than 60 percent. Therefore, higher urban rural differential in literacy rate may be attributed to the fact that the educational opportunities among most of these districts are very poor in rural areas and rural people are mostly engaged in primary activities like animal rearing, herding and occasional agriculture. One of the most important fact behind this urban rural differential in literacy rate may due to the dominance of SC and ST especially in western part. The literacy rate among these social groups is very low, because of their backward socio-economic conditions. The literacy rate of scheduled caste/scheduled tribe population in Rajasthan are 59.75 per cent and 52.80 percent, respectively, which is much lower than the state average literacy rate of 66.11 percent.

There are only four districts which fall under this category of very high urban rural differential in literacy rate, 0.50 percentage point and above. These four districts named as Sirohi (0.54), Banswara (0.55), Udaipur (0.53) and Pratapgarh (0.56) are located in the southern part of the state and are in the proximity of northern Gujarat and western Madhya Pradesh. Table 2 reveals that the urban literacy rate of all the districts except Sirohi (78.70) is above 80 percent. Similarly all the districts reveals rural literacy rate below 60 percent except Sirohi with the lowest rural literacy rate of 49 percent. These four districts which constitute only 7.55 percent of the total geographical area of Rajasthan reveals the fact that there has been a continuous improvement in the literacy rate both in rural and urban area of Rajasthan especially in the census year 2001, when the average state literacy rate jumped from 30.79 percent to 60.41 percent.
Similarly in rural area literacy rate increased from 24.10 percent in 1991 to 55.34 in 2001, registered an increase of 31.24 percentage point, whereas urban literacy rate increased from 53.35 percent in 1991 to 76.20 percent in 2001, with an increase of 22.85 percentage point which islesser than the increase in rural literacy rate. Census year 2011 also reveals that the increase in rural literacy rate is higher than the increase in urban literacy rate. In 1951, a year after Rajasthan came into existence in 1949 , the status of education was very low. State average literacy was only 8.38 percent, whereas the rural literacy was 4.97 percent and urban literacy was 24.68 percent. Although the pace of progress during first four decades was rather slow, but the growth in literacy rate during 1991-2001 and even during 2001-2011, although slow, have raised a hope. This hope may be attributed to the fact that almost all villages in Rajasthan have been covered by at least primary schools. Rajiv Gandhi Swaran Jayanti schools have been opened in thousands of hamlets to ensure that no child should walk more than one kilometer from their home to school. Apart from this other government initiatives like, District primary education programme, Shiksha Karmi and Lok Jumbish programmes have contributed a lot towards spreading education in rural areas to.

\section{Correlation Analysis}

Correlation matrix has been prepared to find out the relationship between all the twenty four independent variables and compared them with each other, as well a simple coefficient of correlation between urban-rural differential index and each of the independent variables have been computed and tested at $99 \%$ and $95 \%$ level of confidence, with the assumption that correlation exists in all cases.

To find out the correlation between urban-rural differential in literacy rate and other independent variables Karl Pearson's method of coefficient correlation has been adopted. Two variables are said to be correlated when increase or decrease in one corresponds with the increase or decrease in other. Out of twenty four variables, eleven aresignificant at 99 percent level of confidence in their relationship with urban-rural differential index in literacy rate. Out of this eleven variable only four variables, named as sex ratio $(r=0.47)$, urban literacy rate $(\mathrm{r}=0.63)$, S.T. population to total population $(\mathrm{r}=$ $0.65)$, total workers to total population $(\mathrm{r}=0.54)$ are positively correlated with urban-rural differential in literacy rate. These four variables show a medium level of positive correlation with urban-rural differential index (medium level of positive correlation +0.25 to +0.75 ). Apart from these four variables rest of the seven variables named as villages having senior secondary school $(\mathrm{r}=-0.53)$, total literacy rate $(\mathrm{r}=-0.78)$, rural literacy rate $(\mathrm{r}=-0.90)$, total male literacy rate $(\mathrm{r}=-0.79)$, total female literacy rate $(\mathrm{r}=-0.79)$, total female literacy rate $(\mathrm{r}=-0.70)$, S.C. population $(\mathrm{r}=-0.63)$ and villages having credit societies $(\mathrm{r}=-0.46)$ are negatively correlated with urban-rural differential index. Out of these seven variables, four indicate that the strength of relationship is of medium level of correlation in negative direction (medium level of negative correlation -0.25 to -0.75 ), whereas, rest of the three indicate the strength of relationship is of high level in negative direction (high level of negative correlation - 0.75 to -1). Apart from these seven variables which are significant at $99 \%$ level of confidence, there are five variables, which are significant 
at $95 \%$ level of confidence in their relationship with urbanrural differential index in literacy rate. Out of these five variables, only two variables, named as rural population to total $(r=0.35)$, Agricultural laborers to total workers $(r=0.41)$ are positively associated and the strength of correlation is of medium level (medium level of positive correlation +0.25 to +0.75 ), whereas, three remaining variables named as, villages having middle school $(\mathrm{r}=-0.38)$, villages having secondary school $(r=-0.48)$, urban population to total population $(r=-$
0.35) are negatively correlated with urban-rural differential index and the strength of correlation are of medium level. Out of the remaining eight variables, household industries to total workers indicates no correlation $(\mathrm{r}=0.00)$ and there is only one variable, named as, cultivators to total workers $(0.01)$ is positively correlated and the strength of relationship is of low level and rest of the variable are correlated in negative direction.

Table 3: Coefficient of correlation for urban - rural differential in literacy and its correlates 2011

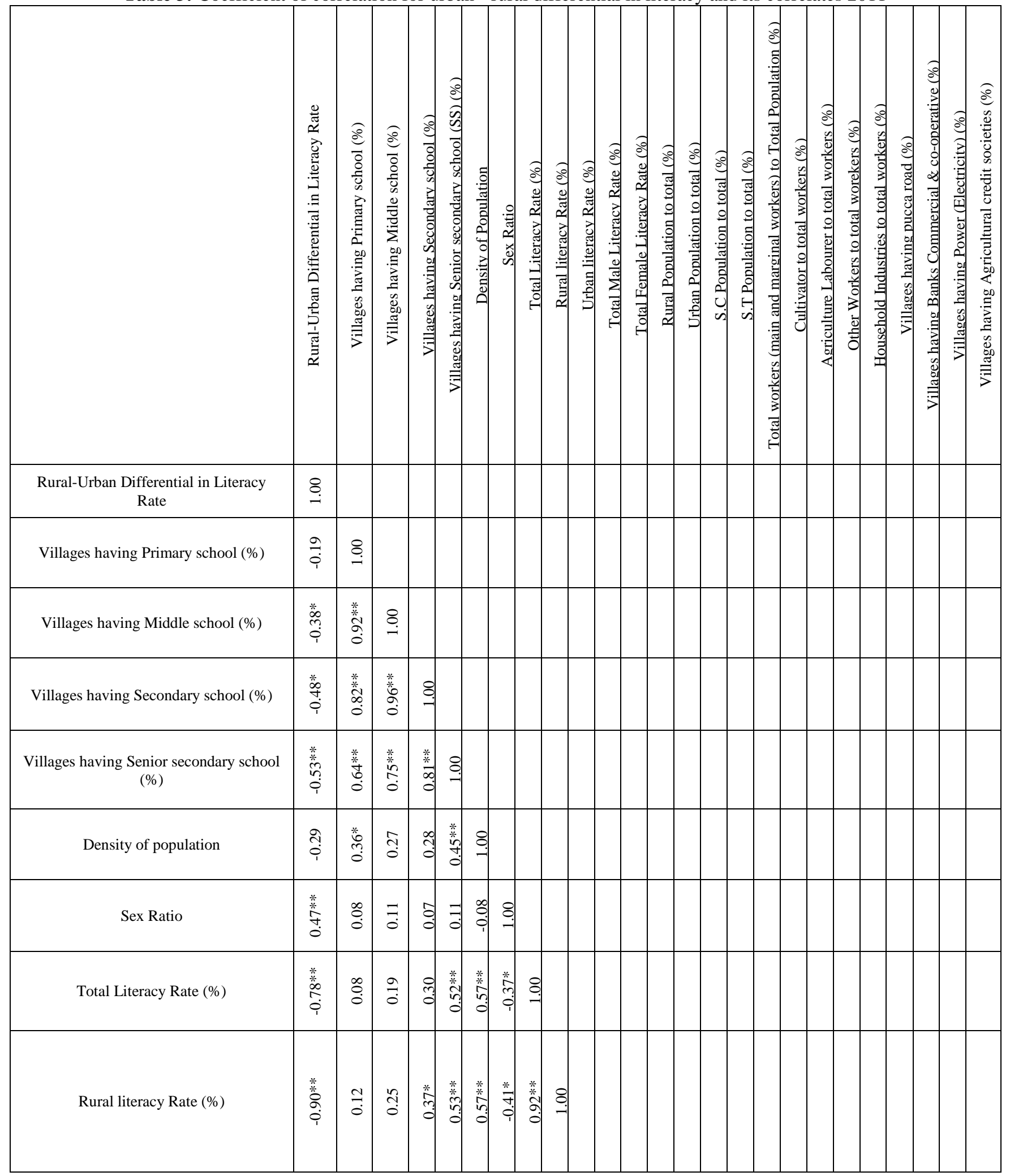




\begin{tabular}{|c|c|c|c|c|c|c|c|c|c|c|c|c|c|c|c|c|c|c|c|c|c|c|c|c|c|}
\hline Urban literacy Rate (\%) & 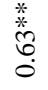 & 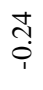 & $\begin{array}{l}\stackrel{*}{g} \\
\stackrel{\leftrightarrow}{i}\end{array}$ & & స̂. & กै? & กे & 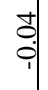 & กิ. & 용 & & & & & & & & & & & & & & & \\
\hline Total Male Literacy Rate (\%) & 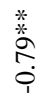 & స̊ & ָे & ?. & c. & $\begin{array}{l}* \\
* \\
\stackrel{*}{*} \\
\stackrel{0}{0} \\
0\end{array}$ & m. & : & $\frac{*}{a}$ & 용 & : & & & & & & & & & & & & & & \\
\hline Total Female Literacy Rate (\%) & 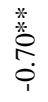 & $\begin{array}{l}0 \\
\dot{\varphi}\end{array}$ & $\exists$ & ป̊. & 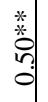 & $\begin{array}{l}* \\
* \\
\text { *ै } \\
0\end{array}$ & 충 & 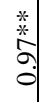 & $\begin{array}{l}* \\
* \\
* \\
0 \\
0 \\
0\end{array}$ & ?요 & 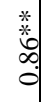 & \&: & & & & & & & & & & & & & \\
\hline Rural Population to total (\%) & $\stackrel{*}{*}$ & $\stackrel{8}{0}$ & 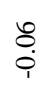 & $\frac{a}{8}$ & 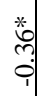 & $\stackrel{\overbrace{}}{?}$ & $\stackrel{\infty}{\circ}$ & 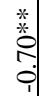 & $\begin{array}{l}* \\
\\
\\
\\
\end{array}$ & ?: & 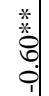 & 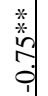 & $\stackrel{8}{-}$ & & & & & & & & & & & & \\
\hline Urban Population to total (\%) & $\begin{array}{l}* \\
\stackrel{*}{n} \\
\stackrel{n}{p} \\
i\end{array}$ & $\stackrel{8}{\circ}$ & $\stackrel{8}{0}$ & ㄱ. & 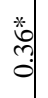 & $\stackrel{\overbrace{}}{3}$ & $\frac{\infty}{0}$ & $\begin{array}{l}* \\
\stackrel{*}{*} \\
\stackrel{*}{0} \\
\vdots\end{array}$ & $\frac{*}{y}$ & $\stackrel{1}{0}$ & 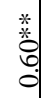 & 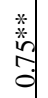 & 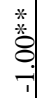 & \&:- & & & & & & & & & & & \\
\hline S.C Population to total (\%) & 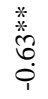 & \begin{tabular}{l}
\multirow{1}{*}{} \\
$\stackrel{1}{1}$
\end{tabular} & 苂 & $\stackrel{\infty}{0}$ & $\stackrel{t}{0}$ & $\frac{0}{0}$ & 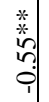 & $\begin{array}{l}* \\
\text { ôt. } \\
0\end{array}$ & 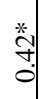 & 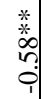 & : & 葛 & กे. & ลे & - & & & & & & & & & & \\
\hline S.T Population to total (\%) & \begin{tabular}{l}
$*$ \\
\multirow{*}{*}{} \\
$\stackrel{0}{0}$ \\
$\stackrel{0}{0}$
\end{tabular} & $\stackrel{8}{0}$ & 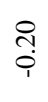 & సे| & ले & ㄱ. & $\stackrel{*}{\forall}$ & 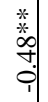 & \begin{tabular}{l}
$*$ \\
\multirow{y}{*}{} \\
$\dot{\varphi}$ \\
\end{tabular} & $\begin{array}{l}* \\
* \\
* \\
*\end{array}$ & 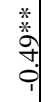 & 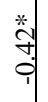 & \begin{tabular}{l}
$*$ \\
$*$ \\
$*$ \\
\multirow{*}{*}{} \\
0
\end{tabular} & 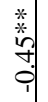 & \begin{tabular}{l}
$*$ \\
\multirow{2}{*}{} \\
$\stackrel{2}{1}$
\end{tabular} & $\stackrel{8}{-}$ & & & & & & & & & \\
\hline $\begin{array}{l}\text { Total workers (main and marginal } \\
\text { workers) to Total Population (\%) }\end{array}$ & $\begin{array}{l}\text { * } \\
\text { 草 } \\
?\end{array}$ & $\begin{array}{l}\stackrel{*}{*} \\
\stackrel{+}{+} \\
\stackrel{\leftrightarrow}{i}\end{array}$ & 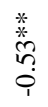 & 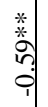 & 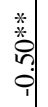 & $\frac{0}{1}$ & ते. & \begin{tabular}{l}
$*$ \\
\multirow{*}{*}{} \\
$n$ \\
$n$ \\
$?$
\end{tabular} & 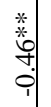 & ले & 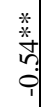 & 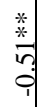 & $\begin{array}{l}* \\
\text { *a } \\
\\
0\end{array}$ & 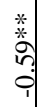 & సे. & : & \&:- & & & & & & & & \\
\hline Cultivator to total workers (\%) & $\ddot{\circ}$ & $\frac{ \pm}{0}$ & $\frac{1}{0}$ & \pm & 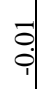 & $\frac{ \pm}{0}$ & $=$ & ?ֶ: & 으. & 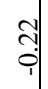 & 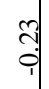 & $\begin{array}{l}* \\
* \\
m \\
0 \\
0\end{array}$ & $\begin{array}{l}* \\
\stackrel{*}{*} \\
0 \\
0\end{array}$ & $\begin{array}{l}* \\
* \\
0 \\
0 \\
0\end{array}$ & in & $\stackrel{m}{0}$ & ิิ & 웅 & & & & & & & \\
\hline $\begin{array}{l}\text { Agriculture Laborers to total workers } \\
\qquad \%)\end{array}$ & $\stackrel{*}{\forall}$ & @़ & $\begin{array}{l}* \\
\infty \\
\substack{0 \\
i}\end{array}$ & 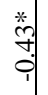 & $\begin{array}{c}* \\
* \\
n \\
c \\
c\end{array}$ & $\frac{9}{9}$ & ลे. & $\stackrel{*}{*}$ & 俈 & & $\begin{array}{l}* \\
\cdots \\
0 \\
0 \\
1\end{array}$ & ?. & ลิ. & 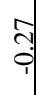 & $\frac{9}{0}$ & 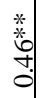 & $\stackrel{*}{c}$ & ?े. & \& & & & & & & \\
\hline Other Workers to total workers (\%) & $\begin{array}{l}\bar{n} \\
\stackrel{\rho}{p}\end{array}$ & $\stackrel{\leftrightarrow}{0}$ & $\stackrel{8}{0}$ & $\frac{\pi}{0}$ & กี & $\stackrel{\infty}{\stackrel{\infty}{~}}$ & 궁 & 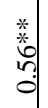 & ते. & $\stackrel{\nabla}{0}$ & 蒡 & *. & 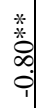 & 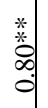 & ๙ุ. & $\stackrel{*}{\stackrel{*}{m}}$ & 苂. & 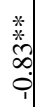 & సิ & \&: & & & & & \\
\hline $\begin{array}{l}\text { Household Industries to total workers } \\
\qquad(\%)\end{array}$ & $\stackrel{8}{0}$ & 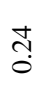 & $\stackrel{n}{0}$ & t) & $\frac{5}{0}$ & $\stackrel{\beth}{0}$ & å & กै & $\stackrel{8}{\circ}$ & $\frac{m}{0}$ & 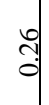 & ֻُ & \begin{tabular}{l}
$*$ \\
$*$ \\
\\
\hdashline \\
$i$
\end{tabular} & $\frac{*}{*}$ & 용. & $\stackrel{+}{i}$ & $\begin{array}{l}* \\
* \\
\\
i\end{array}$ & : & 官 & 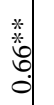 & : & & & & \\
\hline Villages having pucca road (\%) & $\begin{array}{l}\text { Ṭ } \\
\text { }\end{array}$ & $\begin{array}{l}\text { * } \\
\stackrel{*}{*} \\
\stackrel{\infty}{0}\end{array}$ & $\begin{array}{l}\text { * } \\
\stackrel{*}{\circ} \\
\stackrel{0}{\circ}\end{array}$ & 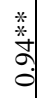 & \begin{tabular}{l}
$*$ \\
\multirow{*}{*}{} \\
$\stackrel{*}{0}$ \\
0
\end{tabular} & $\frac{n}{0}$ & 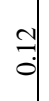 & $\stackrel{\infty}{0}$ & $\approx$ & $\begin{array}{l}* \\
\forall \\
\text { : } \\
\end{array}$ & - & ș & ș. & ș. & : & $\frac{0}{0}$ & \begin{tabular}{l}
$*$ \\
$*$ \\
$*$ \\
\multirow{7}{*}{} \\
$\stackrel{1}{1}$
\end{tabular} & 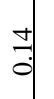 & ?े & $\stackrel{d}{0}$ & $\stackrel{\circ}{0}$ & 8. & & & \\
\hline $\begin{array}{c}\text { Villages having Banks Commercial \& } \\
\text { co-operative }(\%)\end{array}$ & $\stackrel{\substack{0 \\
i}}{i}$ & $\begin{array}{l}\stackrel{*}{*} \\
\stackrel{*}{*}\end{array}$ & $\begin{array}{l}\text { * } \\
\stackrel{*}{*} \\
\stackrel{0}{0} \\
0\end{array}$ & 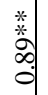 & $\begin{array}{l}* \\
\stackrel{*}{*} \\
0\end{array}$ & $\stackrel{0}{\circ}$ & $\stackrel{0}{0}$ & $\stackrel{?}{\circ}$ & : & 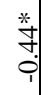 & $=$ & $\stackrel{d}{0}$ & $\begin{array}{l}\infty \\
0 \\
0 \\
\end{array}$ & $\stackrel{\infty}{\circ}$ & $\overline{0}$ & กิ & 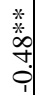 & 의. & $\stackrel{+}{m}$ & 용. & 용 & 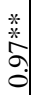 & - & & \\
\hline Villages having Power (Electricity) (\%) & $\stackrel{\hat{n}}{i}$ & @ొ & $\stackrel{*}{\stackrel{*}{*}}$ & 今े & ? & $\stackrel{*}{\stackrel{*}{\sim}}$ & 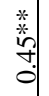 & $\begin{array}{c}* \\
\cdots \\
0 \\
0\end{array}$ & $\approx$ & ç & 节 & 光 & 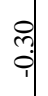 & ले & $\frac{1}{0}$ & 气. & ?. & กิ & : & ڤุ. & $\stackrel{\square}{0}$ & ?. & \%े & 8 & \\
\hline $\begin{array}{c}\text { Villages having Agricultural credit } \\
\text { societies }(\%)\end{array}$ & $\begin{array}{l}\text { *. } \\
\text { *. } \\
+ \\
+ \\
+\end{array}$ & $\begin{array}{l}\stackrel{*}{*} \\
\stackrel{*}{\hat{\sigma}} \\
\stackrel{0}{0}\end{array}$ & \begin{tabular}{l}
$*$ \\
\multirow{*}{*}{0} \\
$\infty$ \\
0
\end{tabular} & $\begin{array}{l}* \\
* \\
* \\
\infty \\
0 \\
0\end{array}$ & 菊 & $\stackrel{8}{0}$ & $\stackrel{8}{\circ}$ & กิ & 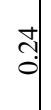 & 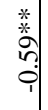 & 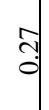 & : & $\frac{9}{i}$ & $\frac{0}{0}$ & ஸे & 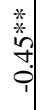 & $\begin{array}{l}* \\
* \\
* \\
* \\
0 \\
0\end{array}$ & $\overrightarrow{0}$ & $\begin{array}{l}* \\
0 \\
m \\
0 \\
0\end{array}$ & ?. & $=$ & $\frac{*}{2}$ & วั & वे & $\stackrel{\circ}{\circ}$ \\
\hline
\end{tabular}

Note: - **Significant at $99 \%$ level of confidence; *Significant at $95 \%$ level of confidence

SOURCE: Calculated by author on the basis of data obtained from District Census Handbook 2011 (Office of the Registrar General of India and Census Commissioner, Government of India) 


\section{Conclusion}

Literacy is one of the most important demographic attributes and most difficult issue, which the people of developing countries like India, are facing today. Apart from disparities in male and female literacy rate, there is a wide spread disparity in urban rural literacy rate. Urban rural differential in literacy rate results from the variation in socio-economic condition of the rural and urban area. Like other innovation literacy starts from urban areas and subsequently diffuses to rural areas and the growth in literacy rate depends upon the intensity of the interaction between urban and rural areas. Predominantly agrarian economy and social values do not provide congenial atmosphere for the spread of literacy in rural areas. Therefore, marked difference in literacy rate between urban and rural can be perceived. This research paper reveals that there exists a wide gap between the literacy rate of urban and rural areas. The rural urban differential in 1951, just after the formation of Rajasthan in 1949 was 2.35 percentage point, which declined to 1.76 percentage point in 1961 , since then, there has been a continuous decline in urban rural differential in literacy rate in Rajasthan. Over the decades urban-rural differential in literacy rate continued to narrow down and reached up to 0.28 in 2011. Similarly the gap between the urban and rural literacy rate also narrowed down with rural literacy rate of 61.44 percent and urban literacy rate of 79.68 percent in 2011 . The analysis at district level in the census year 2011, clearly indicates that there is a wider gap between the urban and rural literacy rate. It has been observed that the urban-rural indices in the western and southern districts, i.e. Jaisalmer, Bikaner, Jalor, Sirohi, Banswara, Udaipur and Pratapgarh are relatively high as compared to eastern and northern part of the state of Rajasthan. The districts having low urban-rural differentials are characterized by urbanization, high literacy rate, educational facilities, agricultural development and communication facilities like pucca road etc. The districts which are located in north and east of the state like, Ganganagar, Hanumangarh, Jhunjhunu, Dhaulpur, Sikar, and Bharatpur reveal low differential index, due to their proximity to Haryana and Punjab in the north and Uttar Pradesh in the east, and nearness to national capital, New Delhi, which provides better opportunities in terms of employment and education. These districts are marked by relatively higher urbanization, communication and educational facilities. Government should pay attention to elevate the economic conditions of districts having high urban-rural differential in literacy rate. So that they may come up with improved socioeconomic conditions, which would lead to narrowing down of urban-rural differential in literacy rate.

\section{References}

[1] Azim, S. (2005), Literacy growth disparities in Karnataka. Economic and Political Weekly, 40(16), 1647-1649.

[2] Ali I, Reddy R (1995). India's Population Problem: A Sociological Study,India J. Reg. Sci., 27(1): 2.

[3] Chandana, R.C. (2009). Literacy in Punjab and Haryana2001. Punjab Geographer, 5, 116-120.

[4] D'Souza VS (1982). Rural-Urban Disparities: Education, DemographyIndia, 11(2): 202-205.
[5] Frey, R. S. \& Field, C. (2000). The determinants of infant mortality in the less developed countries: cross-national test of five theories. Social Indicators Research,52, 215234.

[6] Gurumurthy G (1976). Fertility Differentials in Andhra Pradesh-1961,Demogr. India, 5(1;2): 153-162.

[7] Hassan, M. I. (2005). Population Geography.Rawat Publications, Jaipur.

[8] Jhariya, G. P. \& Jain, C. K. (2014). Pattern and differential of literacy in Madhya Pradesh. IOSR Journal of Humanities and Social Science, 19 (9), 77-84.

[9] Khan, A. Q. (2004). Regional imbalance and changing pattern of literacy in Jammu and Kashmir state (19612001). Population Geography,26 (1, 2), 49-60.

[10] Krishna, G. \& Shyam, M. (1978). Regional aspects of urban-rural differential in literacy in India: 1971. The Journal of Developing Areas,13(1), 11-21.

[11] Mathur BB (1982). Literacy Differentials in Uttar Pradesh: 1971, AnUnpublished M. Phil. Dissertation, Department of Geography PunjabUniversity, Chandigarh

[12] Magadi, M. A., Agwanda, A. O. \& Obare, F. O. (2007). A comparative analysis of the use of maternal health services between teenagers and older mothers in Sub- Saharan Africa: evidence from demographic and health surveys (DMH). Social Science and Medicine,64, 1311- 1325.

[13] Ramotra, K. C. (2003). Spatio-temporal patterns of scheduled caste literacy in Kolhapur and Sangli Districts. In Patil \& R.B. et al., (Eds), Development in India: Anxieties and alternative paradigms (pp. 381- 394). Published by Prof S. N Pawar, Felicitation Committee, Kamala College, Kolhapur.

[14] Siddique M (1977). The Geography of Literacy in Uttar Pradesh, Geogr.Rev. India, 39(4): 374-388.

[15] Shafiqullah, S. (2011). Regional analysis of urban-rural differentials in literacy in Uttar Pradesh, India. Journal of Geography and Regional Planning,4(5), 287-296.

[16] Som, K. S. \& Mishra, R.P. (2014). Literacy and their differential in West Bengal. International Journal of Science and Research,3(6), 1537-1545.

[17] Usha Rao NJ (1981). Inter-State Disparities in Literacy rates inKarnataka with Special Reference to Scheduled Castes, in Bhat, L.S.(ED), Regional Disparities in India, Society for the study of RegionalDisparities, New Delhi. 